\title{
Do Wages Lead Inflation? Swiss Evidence
}

\author{
Attilio Zanetti ${ }^{*}$ \\ JEL classification: E31, J30 \\ Keywords: inflation, wages, unit labour costs, Granger causality
}

\section{Introduction}

In a forward-looking environment, policy makers and market participants are constantly in search of indicators that might help predict future inflation. A wide range of measures of the state of the labour market - such as the gap between the actual and the natural level of unemployment, indicators of excess demand and of labour supply shortages - belong to the standard set of variables monitored by monetary authorities and analysts. In this context, a group of indicators that generally receives substantial attention is the one related to workers' compensations: changes in wages, labour productivity and unit labour costs. The underlying assumption is that wage dynamics play a central role in determining price developments. In particular, if nominal wages increase faster than productivity does, price stability is jeopardised because companies are faced with growing production costs and will eventually be forced to increase their prices. According to this view, appropriate measures of labour cost developments at the aggregate level can be useful as early detectors of future inflation.

In contrast to other countries, wages and labour cost developments have received little attention in Switzerland. The main reason lies in the lack of such indicators. Currently, nominal wage figures are released only once a year by the

* Swiss National Bank, Boersenstrasse 15, Postfach CH-8022 Zurich,Switzerland. E-mail: attilio.zanetti@snb.ch. I am grateful to two anonymous referees for their stimulating suggestions. Earlier drafts of this paper took advantage of the helpful remarks of several collegues at the SNB as well as of participants in the 2006 Annual Meeting of the SSES. I also thank André Farine at the SFSO for his support in gathering the data as well as Cliona Coyne and Helen Baumer for their careful reading of the manuscript. The views expressed in this paper are those of the author and do not necessarily reflect those of the Swiss National Bank. 
Swiss Federal Statistical Office and with quite a substantial delay. No official unit labour cost series exist.

In this paper, we construct quarterly time series for nominal hourly wages and for productivity-corrected nominal hourly wages, i.e. unit labour costs, from 1975 onwards. We then investigate the empirical link between wages and CPI inflation in order to identify causality effects. In particular, we want to evaluate the relevance of wages as an indicator for short-run CPI inflation. Causality here is defined in an econometric sense: it asks whether wages help to improve inflation forecasts beyond the information contained in lagged inflation itself. Evidence of Granger causality of wages on prices would, instead, not mean that wage changes literally cause price changes. If employees are forward-looking, it might actually be that - at least to some extent - wages increase because future prices are correctly anticipated to rise. It would, however, imply that current wage developments carry information regarding future inflation movements.

We find evidence that prices influence wages, independently of the sample period. Wages also influence prices, in the full sample. This result, however, does not hold for the sub-sample starting at the beginning of the 1990s, implying that the explanatory power of wages vanishes in a low inflation environment.

The paper is structured as follows. Section 2 presents some theoretical arguments linking wages and prices. It also provides an overview of some recent empirical work based on US data and refers to results obtained by GAILLARD (1992) for Switzerland. Section 3 looks briefly at the Swiss data. In Section 4, we formally investigate the terms of the relation between wages and prices in Switzerland. This section also deals with generated regressors issue and the safety measures taken to ensure correct inference. Section 5 contains some concluding remarks.

\section{The Link between Wages and Prices}

\subsection{Theoretical Background}

Labour cost developments are often said to lead inflation. This argument goes back to the cost-push theory of inflation, which maintains that because labour costs make up a substantial share of the production costs, rising wages will sooner or later end up influencing prices. In particular, if wages grow faster than labour productivity, companies are forced to pass on the cost increase and thus adjust prices. Certainly, the link is not mechanical. The literature on nominal price rigidity indicates that companies on most markets tend to avoid making 
all too frequent price changes. The rate at which adjustments occur depends on a series of factors such as the size and persistency of the cost increase, the size of the profit margins, the demand strength and the expected behaviour of competitors. In the short run, companies might be willing to accept a reduction in their profit margins, but in the medium term, persistent wage increases make price adjustments necessary.

This argument, however, does not resolve the issue of how an acceleration in labour costs comes about in the first place. The bulk of existing explanations regarding inflation are actually provided by demand-driven theories. These identify in an excessively expansionary monetary policy the exogenous determinant of inflationary pressures. A causal influence of wages on prices could in principle still be observed. As companies compete to hire staff in order to satisfy a growing demand, wages will rise unless labour supply is sufficiently elastic. Note, however, that the direction of causation might just as well be inverted: strong aggregate demand, capacity bottlenecks and aggregate supply shortages could allow companies to increase prices, leading to higher profits. This would in turn push employees to request substantial wage increases. Either way, this view implies that wages are likely to lose their interest as an early indicator for future inflationary trends and that the focus should rather be placed on monetary conditions. Obviously, the different mechanisms that have just been sketched might be working simultaneously, allowing for bi-directional influences between wages and prices.

Two alternative settings are generally used to model wage behaviour: the Phillips curve and the wage curve. ${ }^{1}$ Whereas the Phillips curve approach is based on a negative relationship between the rate of change of wages and the unemployment rate (or some broader measure of economic slack), the wage curve implies a negative relationship between the level of real wages and the unemployment rate. In OECD (1997, table 1.A.1), wage equations are estimated for twenty-one countries. In seven of these, the Phillips curve proves to provide a better fit of the data. This group of countries includes the US and Switzerland. This is why, following Gordon (1985), Ghali (1999) and Mehra (2000), we formalise the link between the two variables in an expectations-augmented Phillips curve framework, where prices are determined by a mark-up over wages. In turn, wages depend on expected inflation. In both equations, aggregate demand conditions as well as supply shocks are also taken into account. The two equations can be formulated as follows:

1 See Layard, Nickell and Jackman (1991) Blanchard and Katz (1999) and Bardsen, Eitrheim, Jansen and Nymoen (2005) for a discussion. 


$$
\begin{gathered}
\Delta p_{t}=\alpha_{p}+\beta_{1 p} \Delta(w-q)_{t}+\beta_{2 p} d_{t}+\beta_{3 p} z_{p t} \\
\Delta(w-q)_{t}=\alpha_{w}+\beta_{1 w} \Delta p_{t}^{e}+\beta_{2 w} d_{t}+\beta_{3 w} z_{w t} \\
\text { given } \\
\Delta p_{t}^{e}=\sum_{i=1}^{n} \lambda_{i} \Delta p_{t-i} .
\end{gathered}
$$

where $p_{t}$ is the price level, $w_{t}$ is the nominal wage, $q_{t}$ is labour productivity, $d_{t}$ is a measure of the state of aggregate demand, $z_{p t}$ are price-specific supply shocks while $z_{w t}$ are wage-specific supply shocks. $\Delta$ is the first difference operator and $\Delta p_{t}^{e}$ denotes inflation expectations. All variables are expressed in natural logarithms.

The price equation (1) implies that prices are determined by wage behaviour, once you control for the cyclical state of demand, on the one hand, and supply shocks, on the other. Equation (2) describes the wage dynamics. Firstly, note that wages are defined as labour productivity-adjusted wages, i.e. unit labour costs. Secondly, given the assumed adaptive shape of inflation expectations, expected inflation is explicitly related to past inflation in the wage equation once (3) is substituted in. Wage growth is thus influenced by lagged price inflation. In other words, this setting suggests that both wages and prices systematically influence each other. The next section looks at what empirical research on the topic says.

\subsection{Empirical Evidence}

So far, attempts to empirically investigate the link between wages and prices have produced contrasting results. Most of the available research seems to show little evidence that wage inflation causes price inflation. Gordon (1988) and MeHra (1991) conclude that wage changes are not relevant in explaining inflation when the latter is measured using the GDP deflator. MeHra (1993) finds that changes in unit labour costs cause CPI inflation; stronger evidence, however, supports the view that changes in the GDP price deflator explain wage changes. Based on further research, this same author (MEHRA, 2000) argues that wage growth helps predict future inflation only during a period of constantly accelerating inflation. In contrast, inflation systematically helps predict wage growth over a much larger span of time (1952-1999) which covers different inflation regimes. Emery and Chang (1996) observe that, during the post-1980 period of rather low inflation, including a unit labour cost variable in the inflation equations does 
not improve their out-of-sample forecasting power, whereas evidence of inflation causing wage growth is robust, regardless of the sample choice. Hess and SCHweitzer (2000) also find evidence that inflation helps predict labour costs rather than the other way around.

Some authors have identified an impact of wages on prices at the sector level. BRAUER (1997) shows that while compensation growth in the goods industry has little predictive power for the evolution of goods prices, compensation growth in the private services sector does help predict prices for a specific group of services, and thus in turn movements of the CPI. AAronson (1999) provides evidence of the impact of minimum-wage increases on prices in the catering sector.

CHAN-LAU and TOCKARICK (1999) claim that moderate labour cost growth due to a weakening in the dynamics of non-wage labour compensation and greater labour productivity gains - is a key determinant of the slowdown in inflation in the second half of the 1990s in the United States. Against the background of a growing output gap and declining unemployment, extending the Phillips curve specification with a measure of labour costs turns out to be necessary in order to explain the otherwise puzzling decline in inflation. Investigating the 1959-1989 period, GHALI (1999) asserts that causality essentially runs from wages to prices and takes a clear stance in favour of the systematic monitoring of labour costs for monetary policy purposes.

Clearly, even from an empirical perspective, there is no agreement on the terms of the relationship between wages and prices. Generally speaking, research results are quite sensitive to the sample choice, to the specific labour cost and price measures adopted as well as to the way econometric tests are specified.

In the case of Switzerland, findings on this issue are contained in Gaillard (1992), covering the period 1966:1-1991:4. The author formulates a two-equation framework to evaluate the wage-price adjustment mechanism. In the price equation, prices are measured as the GDP deflator. Two formulations are applied. In the first one, prices are determined by unit labour costs and a time-varying mark-up which depends on business cycle conditions as measured by capacity utilisation. In the second formulation, prices are a function of a constant mark-up over production costs (defined as the sum of unit labour costs and capital costs). In both cases, it turns out that unit labour costs play a highly significant role for the short-run dynamics of prices. For the wage equation, too, several specifications are tried. Results across the board show that lagged price changes are a key determinant of short-run wage developments.

This work expands GaILLARD's (1992) results in a number of different ways. First of all, we explicitly focus on the link between wages and CPI changes: our purpose is to evaluate whether the movements of unit labour costs contain 
information for future headline inflation. Second, our wage and unit labour cost series are based on a more comprehensive definition. Third, we extend the analysis period up to 2005 , thereby including the moderate inflation environment which has now been observed for more than ten years.

\section{Swiss Data}

\subsection{Introducing the Series}

At the moment in Switzerland, no official quarterly wage and unit labour cost data exist. Official labour productivity data are published with a substantial delay and are available on an annual basis only. As a consequence, the quarterly series used in our analysis had to be constructed.

As far as wages are concerned, we used the annual labour income data resulting from the national accounts as a starting point. Labour income is defined as the total amount of gross wages paid by resident employers to their resident and non-resident workers. This definition of labour income also covers one-off compensation (bonuses and benefits) as well as changes in charges due to pay-roll taxes. Data currently cover the period to 2005. We obtained higher frequency observations by applying the CHOw and LiN (1971) technique for temporal disaggregation within the ECOTRIM package developed by Eurostat. ${ }^{2}$ Note that this technique is widely applied to obtain quarterly estimates of national accounts ( see Eurostat, 1999). Swiss quarterly accounts data are also estimated according to this principle. By means of linear regression, this method distributes wage growth over the four quarters comprising a year, under the constraint that average quarterly year-on-year changes correspond to the growth rate displayed by the original low frequency series. Also, an assumption must be made regarding the structure of the regression's residuals. The Chow and Lin procedure assumes that residuals follow an AR(1) process. For wage growth to be distributed over the quarters in a legitimate manner, one or more relevant regressors - called related series - must be chosen. Thus, the quarterly pattern of the estimated series is ultimately determined by the profile of the related series which have been selected. The magnitude of growth, instead, is determined entirely by the dynamics of the low frequency series (labour income).

2 See Barcellan (1994) and Eurostat (1999). 
In order to identify appropriate regressors, we followed the strategy suggested by Eurostat (1999). The latter is based on two main criteria: i) the related series used as regressor should have some kind of theoretically-founded link to the target series and ii) statistical evidence on the correlation between the target variable and candidate regressors must support the choice. We used two regressors. The first one is a time series on nominal wage growth obtained on the basis of information taken from the files of SUVA, the Swiss Accident Insurance Fund for employees. In the past, this source was used by the State Secretariat for Economics (seco) to extract official estimates of the nominal wage dynamics on a quarterly basis. ${ }^{3}$ SUVA wages, however, underestimate the actual trend in labour income, as they do not take into account one-off compensations and changes in aggregate workers' income linked with shifts in the employment structure. Indeed, labour income grew, on average, $1.5 \%$ p.a. faster than SUVA wages over the 1975-2005 period. The wage series used by GaILLARD (1992) is affected by these shortcomings. Our second high-frequency regressor, is employment growth, measured in terms of hours worked, which we introduce in more detail below.

How do these two regressors perform in terms of the two above-mentioned criteria? Criterium i) is satisfied as, in principle, labour income growth is indeed supposed to reflect the joint developments of the quantity of labour input and its price. As far as the second criterium is concerned, a standard approach is to look either at correlations or at the fit of the regression. The simultaneous correlations is 0.75 between labour income and SUVA wages and 0.51 between labour income and hours worked. SUVA wages and hours worked, however, are very weakly correlated (0.05). The result of a regression based on annual data looks as follows (t-statistics in brackets):

$$
\begin{array}{rl}
\Delta_{\text {laborincome }_{t}} & =\underset{(2.49)}{1.06}+\underset{(8.10)}{1.13 \Delta S U V A w_{t}}+\underset{(5.34)}{0.92 \text { hoursworked }_{t}}+\varepsilon_{t} \\
{\text { Adj } . R^{2}}^{2} & 0.77 \text { DW }=1.50
\end{array}
$$

Both regressors are highly significant and make it possible to obtain a reasonable fit. All in all, therefore, these two related series appear to conform well to the afore-mentionned criteria. Figure 1 shows these different time series.

3 All in all, the quarterly figures collected in this manner cover the period 1971:1-2005:4. For the period after 1988, we rely on unofficial estimates obtained on the basis of the SUVA row data. 
Figure 1: Wage Series

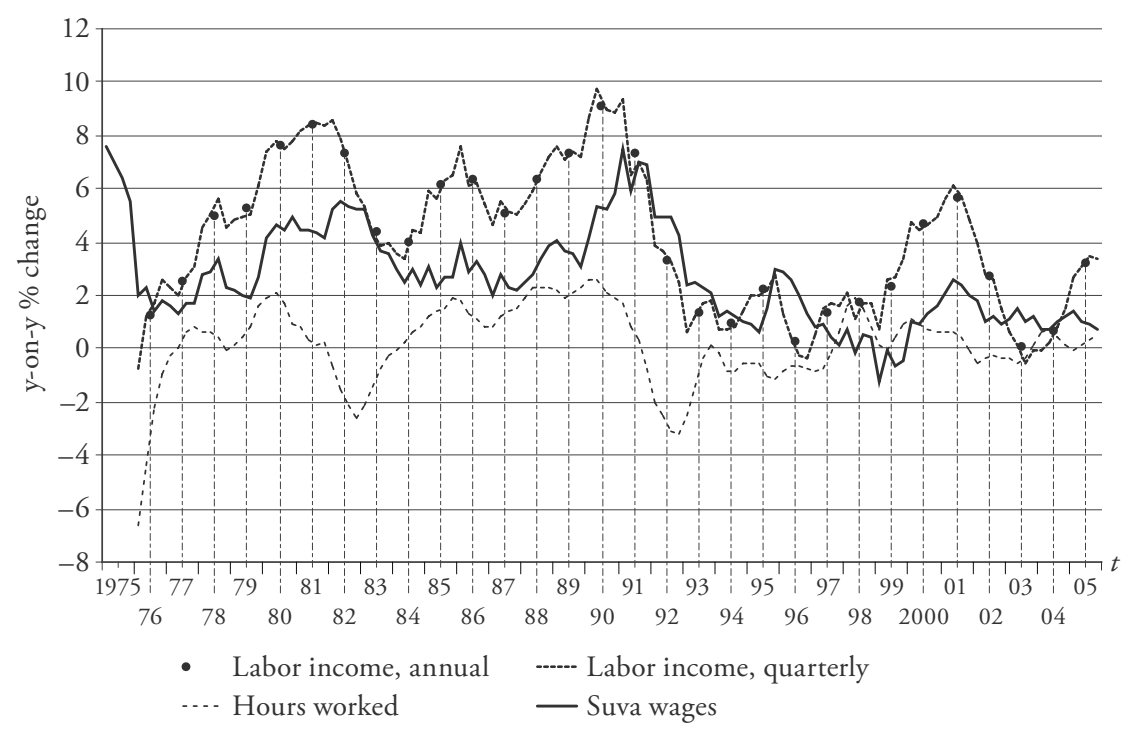

The next step involved computing hourly wage and hourly labour productivity figures. These two series were obtained by dividing labour income and real GDP by a quarterly series of hours worked. Given the significant long-run trend towards shorter average annual work duration - due to phenomena such as the increasing proportion of part-time jobs, longer vacation periods, the reduction of full-time weekly hours - the use of hours worked instead of a pro-capita measure is relevant. Official data on hours worked exist on an annual basis for the period 1991-2004. For our purposes, we constructed an alternative quarterly series based on the active labour force series and on information taken from several sources regarding the different aspects of work duration. ${ }^{4}$ Changes in the Unit Labour Costs (ULC hereafter) were computed as the difference between nominal wage changes and labour productivity changes.

Further, we used a monetary aggregate (M1) as well as a measure of the output gap as indicators of the state of global demand. This latter series results from an

4 Shares of full-time and part-time employment are taken from the quarterly employment statistics of the Swiss Federal Statistical Office (SFSO). Figures on the weekly work duration by employment category, on vacations, absences and additional hours result from the population surveys and the annual labour force surveys. 
SNB internal computation based on the production function approach. All in all, we dispose of a quarterly data set covering the period 1975.1-2005.4. The lower truncation was imposed by our series on hours worked whereas the upper bound of the sample was determined by the lack of further data regarding the nominal labour income. ${ }^{5}$

\subsection{A First Look at the Data}

In this paper, we will compare the evolution of wage inflation and price inflation, where price inflation will be provided by CPI changes. The reason for focusing on the conventional consumer price index rather than on other measures of prices such as the GDP deflator or the producer price index - is that the price stability objective of the monetary authorities is expressed in terms of an upper bound for CPI annual changes. According to the Swiss National Bank (SNB) definition, price stability is provided when CPI annual growth remains below $2 \%$. In this section, however, we will also illustrate the relation between the evolution of wages on the one hand and the producer price index (PPI) on the other.

We start our analyses by considering the relation at the level of producer prices. Fig. $2 \mathrm{a}$ and $2 \mathrm{~b}$ plot the time series of year-on-year changes in the producer price index along with changes in hourly wages (HW) and changes in ULC respectively. The nature of the relation between the two series seems to vary over time. Nonetheless, they clearly share some common major upward and downward movements. As can be seen in Table 1, the simultaneous correlation is 0.58 between PPI changes and nominal wage changes and 0.40 between PPI changes and ULC changes. A careful observation of the two graphs makes it clear that changes in the PPI lead changes in wage inflation. In fact, in the case of Fig. 1a, the correlation between the two series is highest $(0.73)$ between current PPI inflation and changes in nominal wages at time $t+4$. In Fig. 2b, ULC changes appear to reach the maximum correlation with $\mathrm{PPI}_{t}$ changes at $t+4(0.68)$.

Fig. $3 \mathrm{a}$ and $3 \mathrm{~b}$ focus on consumer prices. They show the annual change in the CPI versus our two measures of wage inflation. The two graphs make it even clearer that movements in prices and wages are closely related. The wage series co-move quite systematically with the CPI changes throughout the whole period.

5 The application of the Chow and Lin method makes it possible to estimate out-of-sample values as long as the related series are available. We could therefore extend our sample to 2006:2. Nevertheless, we choose to truncate the analysis in 2005:4 in order to circumvent the issue of the precision of out-of-sample estimates. 
Figure 2a: PPI and Hourly Wages

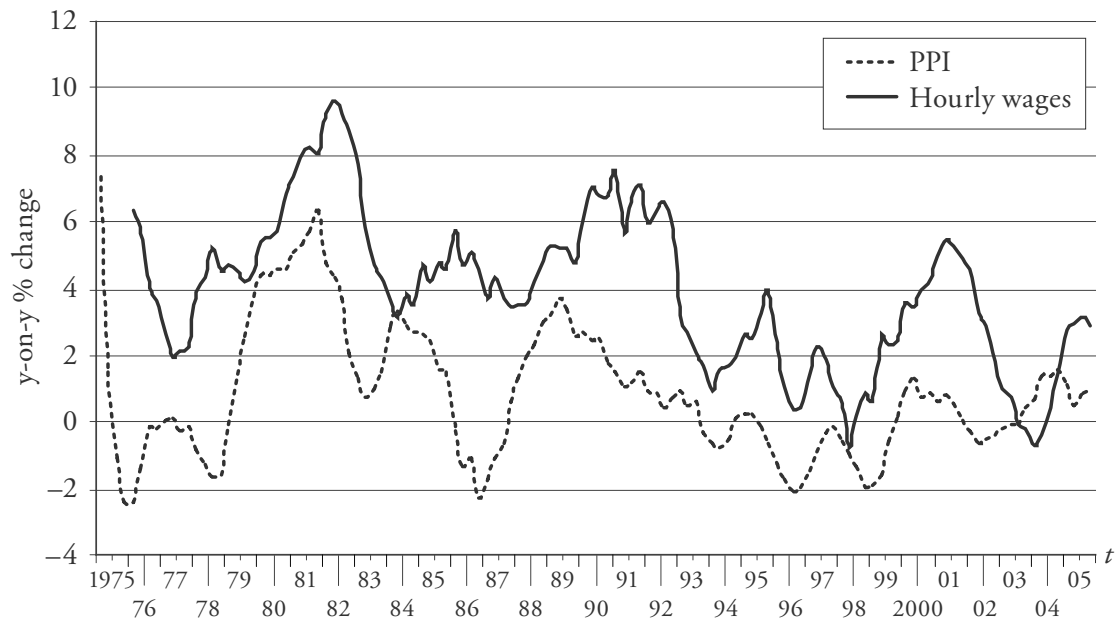

Figure 2b: PPI and Unit Labor Costs

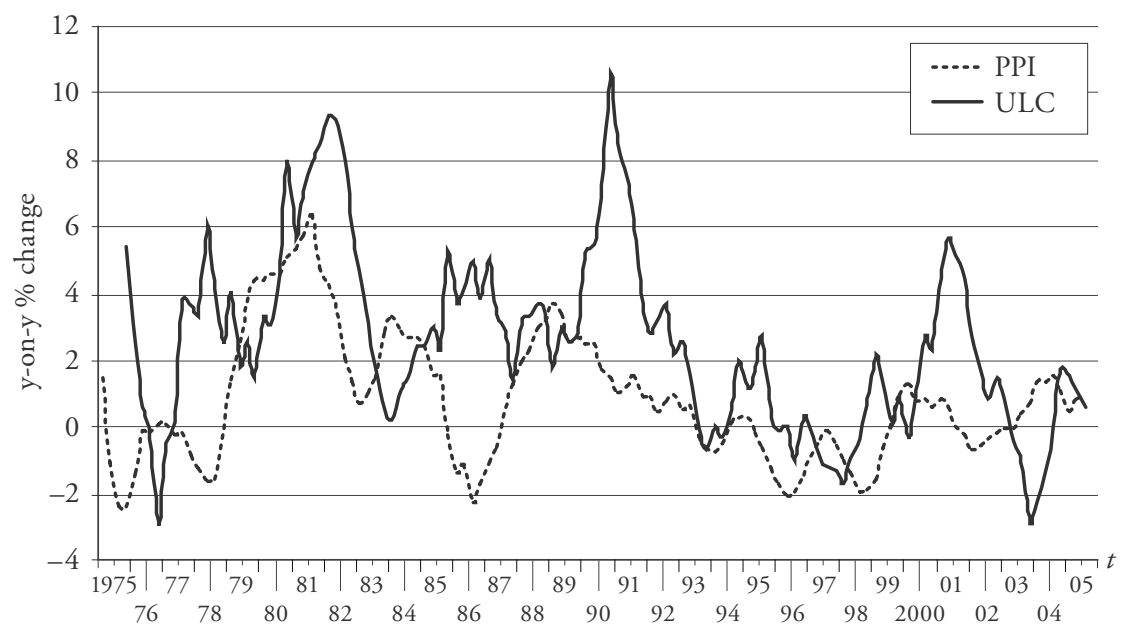


Figure 3a: CPI and Hourly Wages

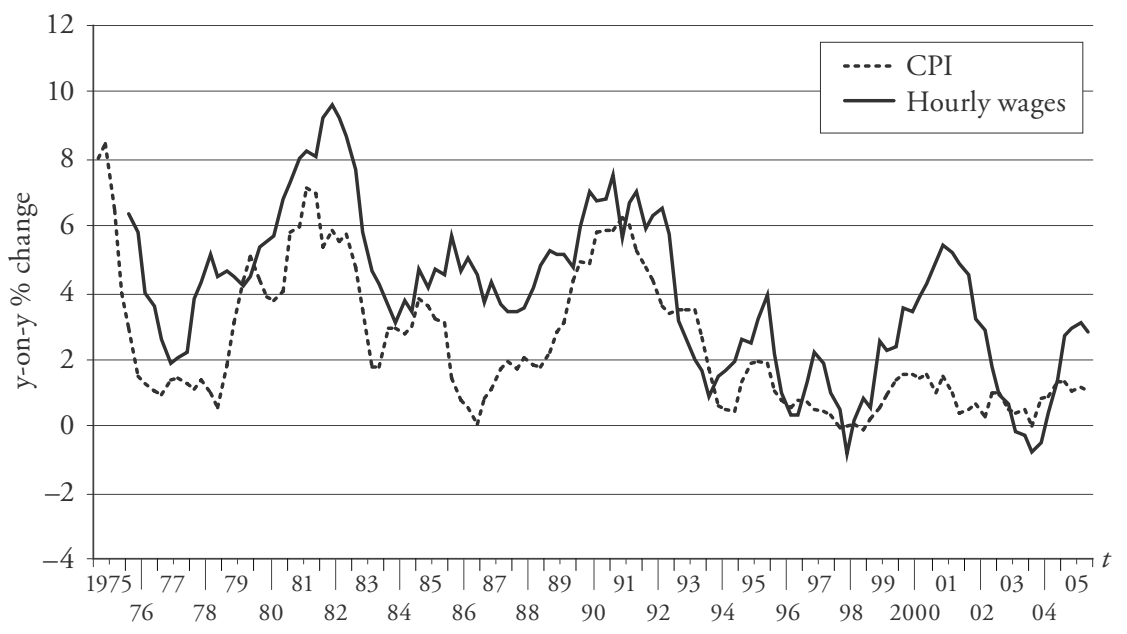

Figure 3b: CPI and Unit Labor Costs

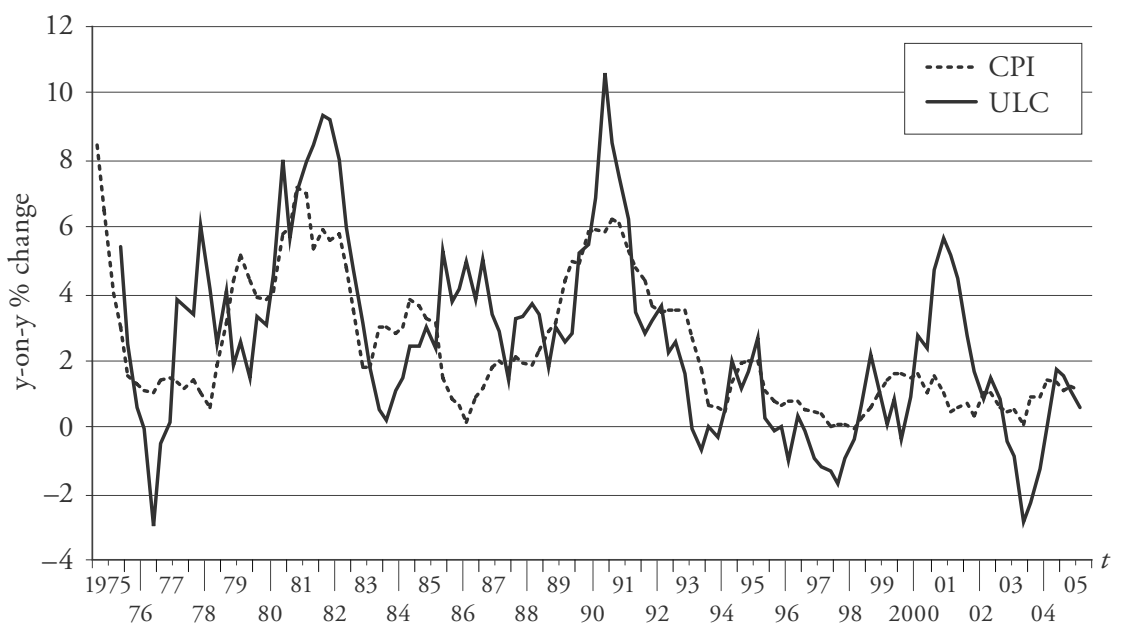


Table 1: Variables' Correlations

\begin{tabular}{ccccc}
\hline$i$ & PPI vs HW $(-i)$ & PPI vs HW $(+i)$ & PPI vs ULC $(-i)$ & PPI vs ULC $(+i)$ \\
\hline 0 & 0.5801 & 0.5801 & 0.3983 & 0.3983 \\
1 & 0.5285 & 0.6484 & 0.3417 & 0.4918 \\
2 & 0.4733 & 0.6997 & 0.3176 & 0.5693 \\
3 & 0.4152 & 0.7318 & 0.2960 & 0.6412 \\
4 & 0.3740 & 0.7331 & 0.2929 & 0.6784 \\
5 & 0.3439 & 0.6937 & 0.3144 & 0.6561 \\
6 & 0.3190 & 0.6301 & 0.3374 & 0.6087 \\
\hline$i$ & CPI vs HW (-i) & CPI vs HW $(+i)$ & CPI vs ULC $(-i)$ & CPI vs ULC $(+i)$ \\
\hline 0 & 0.7819 & 0.7819 & 0.6897 & 0.6897 \\
1 & 0.7252 & 0.7882 & 0.6514 & 0.6844 \\
2 & 0.7148 & 0.7619 & 0.6163 & 0.6576 \\
3 & 0.6555 & 0.7137 & 0.5467 & 0.6154 \\
4 & 0.5914 & 0.6485 & 0.4663 & 0.5578 \\
5 & 0.5203 & 0.5571 & 0.4153 & 0.4866 \\
6 & 0.4405 & 0.4600 & 0.3689 & 0.3915 \\
\hline
\end{tabular}

Correlations refer to year-on-year changes. CPI: consumer price index; PPI: producer price index; HW: hourly wage; ULC: Unit labour costs.

In both graphs, the two series decline strongly at the beginning of the sample. They then display an initial peak in the early 1980s before dropping significantly. They pick up again in a fairly parallel manner at the end of the decade and subsequently follow a common downward trend. A moderate hike is then observed during the cyclical upswing at the beginning of the new millennium. As compared to what has just been observed for the producer price index, the lead of prices on wages is less evident. In fact, in Fig. $3 \mathrm{a}$ and $3 \mathrm{~b}$, the correlations between current CPI and wage changes at $t$ and $t+1$ are equally strong.

By looking at Fig. 2a through 3b, it appears that all individual price and wage growth series are strongly autocorrelated. High pairwise cross correlations are automatically induced by this feature. From a Granger causality perspective, it 
might therefore be interesting to look at how the deviations from the underlying autoregressive processes correlate. For each of the variables, we estimate a simple AR(1) process and have the residuals of the regression define the shocks hitting this variable. We then measure the strength of co-movements between these shocks. In Table 2 we report the correlation results for CPI shocks only. Not reported are similar - but weaker - results for PPI shocks. A ** symbol implies that the correlation is significant at the 5\% level. Generally speaking, Table 2 points to a positive correlation between CPI shocks, on the one hand, and wage or ULC shocks, on the other. Correlations tend to be stronger between CPI shocks and wage growth at time $t+i$, suggesting a possible lead of price inflation on wage inflation. Between CPI shocks and ULC shocks, however, the strongest correlation is the simultaneous one.

Table 2: Shocks' Correlations

\begin{tabular}{ccccc}
\hline$i$ & CPI vs HW $(-i)$ & CPI vs HW $(+i)$ & CPI vs ULC $(-i)$ & CPI vs ULC $(+i)$ \\
\hline 0 & 0.1052 & 0.1052 & $0.1818^{* *}$ & $0.1818^{* *}$ \\
1 & 0.1702 & $0.3050^{* *}$ & 0.0431 & 0.1688 \\
2 & 0.1078 & $0.2124^{* *}$ & 0.1522 & 0.1296 \\
3 & 0.0248 & 0.1268 & 0.0318 & 0.1113 \\
4 & 0.0906 & $0.2130^{* *}$ & -0.1431 & 0.1073 \\
5 & 0.0868 & 0.0647 & -0.009 & 0.1604 \\
6 & -0.0208 & 0.0027 & -0.0939 & -0.0105 \\
\hline
\end{tabular}

** signals significance at the $5 \%$ level.

This initial evidence proves that price and wage changes are closely related. Nonetheless, it does not allow any safe conclusion to be made about the direction of causation. In the next section, Granger-causality tests are implemented to shed some more light on the empirical relationship between wages and prices. 


\section{Empirical Analysis}

\subsection{Unit Root and Cointegration Analysis}

From this point onwards, we will focus on changes in productivity-adjusted wages, i.e. changes in ULC, as the measure for wage inflation. From a theoretical point of view, at least, ULC are a better measure of the cost pressure experienced by companies than simple nominal wage changes. If productivity increases, companies can afford to pay higher wages without changes in their prices.

In order to establish the nature of the link between ULC and prices, we will implement formal Granger-causality and weak exogeneity tests. The specification of all further tests in this paper crucially depends on the stationarity properties of the series. In part of the literature, wages and prices are found to be integrated of order one and Granger-causality tests are formulated in first differences, whereas in some cases wages and prices are considered I(2) and causality tests are consequently implemented using second differences. We perform Augmented DickeyFuller (ADF) as well as Kwiatkowski-Phillips-Schmidt-Shin (KPSS) tests. ${ }^{6}$ Tests are implemented for the CPI and the ULC both in (seasonally-adjusted natural $\log$ ) levels and in first differences.

Table 3 presents the outcome of the test. The upper part of the table reports the estimated values of the $\rho$ coefficient, the ADF test statistics $Z_{D F}$, the number of lags $n$ (according to the SIC) as well as the MacKinnon one-sided $p$-values. The lower part of the table shows the KPSS test statistics as well as the $1 \%$ and $5 \%$ critical values. On the basis of these results, we may conclude that both prices and ULC series are integrated of order one while their log changes are mean stationary.

Next, we analyse the cointegration relationship. If series are cointegrated, a stationary error-correction term must be included in the regressions in order to guarantee correct inference. We regress prices on ULC and implement ADF and KPSS tests for the residuals of this regression. The estimated regressions appear as follows:

$$
\begin{gathered}
p_{t}=4.974+0.909 u c_{t}+\text { resid }_{p, t} \\
u l c_{t}=-5.431+1.090 p_{t}+\text { resid }_{w, t}
\end{gathered}
$$

6 The ADF procedure tests the unit root null hypothesis against the alternative hypothesis that the series are trend stationary or mean stationary. The KPSS procedure, by contrast, tests the null hypothesis of (trend) stationarity. 
The outcome of the ADF and KPSS tests is reported in the lower part of the panels in Table 3. They support the view that residuals of (5) and (6) are stationary, and, thus, that $p_{t}$ and $u c_{t}$ are indeed cointegrated in our sample period. In particular, the KPSS provides strong evidence of stationarity. Although not reported, the results of the Johansen cointegration test also confirm the existance of a stationary linear combination of the two variables.

Note that, in (5) and (6), the estimated coefficients for $u c_{t}$ and $p_{t}$ are very close to one. In fact, Wald tests do not allow this restriction to be rejected. This implies that, in the long run, price increases fully translate into upward nominal wage adjustments. Similarly, nominal wage hikes that are not justified by productivity gains lead to price increases of the same magnitude. ${ }^{7}$

The previous result implies that prices and wages are characterised by a common long-run equilibrium relation. It does not yet explain which one of the two series adjusts to the other, or whether adjustments run in both directions. In order to establish whether cointegration implies some clear-cut form of causality, we test for weak exogeneity. The test is implemented by running the following regressions:

$$
\begin{gathered}
\Delta p_{t}=\alpha_{p}+\beta_{p} e c_{p, t-1}+\sum_{s=1}^{n} \delta_{p s} \Delta p_{t-s}+\varepsilon_{p t} \\
\Delta u l c_{t}=\alpha_{w}+\beta_{w} e c_{w, t-1}+\sum_{s=1}^{n} \delta_{w s} \Delta u l c_{t-s}+\varepsilon_{w t}
\end{gathered}
$$

where $e c_{p}$ and $e c_{w}$ are error-correction terms, i.e. the residuals of the cointegrating regressions estimated above. The optimal number of lags $n$ is again determined on the ground of the Schwarz information criterion. The findings are presented in Table 4. The error-correction term has a significant explanatory power in the both equations. As a consequence, there is no clear evidence of weak exogeneity for either ULC or prices. It cannot be asserted that one of the two variables causes the other in the long run. Deviations from the long-run equilibrium pattern seem to be absorbed by adjustments in both variables.

7 This result differs from what was found in Gaillard (1992), where the estimated long-run wage elasticity of prices turns out to be significantly smaller than one. The author interprets this outcome as evidence of the shortcomings of the wage data set used. 
Table 3: Unit Root and Stationarity Tests

\begin{tabular}{lcccc}
\hline $\begin{array}{l}\text { ADF Test Panel } \\
\text { Variable }\end{array}$ & $\rho$ & $Z_{D F}$ & Lag order & $\begin{array}{c}\text { Mac-Kinnon } \\
\text { p-values }\end{array}$ \\
\hline price level: $p_{t}$ & 0.0001 & 0.06 & 6 & 0.997 \\
ULC level: $u l_{t}$ & -0.0028 & -0.701 & 9 & 0.9702 \\
prices, first differences: $\Delta p_{t}$ & -0.0836 & -3.4696 & 6 & 0.0104 \\
ULC, first differences: $\Delta u c_{t}$ & -0.1356 & -2.7629 & 8 & 0.0669 \\
Equation (5): resid $_{p, t}$ & -0.0219 & -1.6635 & 8 & 0.0908 \\
Equation (6): resid $w_{w, t}$ & -0.0233 & -1.769 & 8 & 0.0731 \\
\hline KPSS Test Panel & & & & $1 \%$ critical value \\
Variable & Test statistics & $5 \%$ critical value & 0.739 \\
\hline price level: $p_{t}$ & 1.2937 & 0.4630 & & 0.739 \\
ULC level: $u l_{t}$ & 1.2673 & 0.4630 & & 0.739 \\
prices, first differences: $\Delta p_{t}$ & 0.5286 & 0.4630 & & 0.739 \\
ULC, first differences: $\Delta u l c_{t}$ & 0.4665 & 0.4630 & 0.739 \\
Equation (5): resid $_{p, t}$ & 0.2420 & 0.4630 & 0.739 \\
Equation (6): resid $_{w, t}$ & 0.2092 & 0.4630 & \\
\hline
\end{tabular}

Table 4: Weak Exogeneity Tests

\begin{tabular}{lcccc}
\hline Regression & $\beta_{p, w}$ & t-statistics & p-value & Lag order \\
\hline Price regression & -0.0113 & -2.127 & 0.0356 & 6 \\
ULC regression & -0.0260 & -1.900 & 0.0602 & 8 \\
\hline
\end{tabular}




\subsection{Granger Causality}

The previous section has highlighted the existence of a long-term co-movement of wages and prices. But what are the dynamics between these two variables in the short run? Cointegration actually implies that at least one of the two variables must adjust to the other in the short term. To investigate the short-run properties of the relationship between wages and prices, we implement Granger causality tests.

In an initial step, we run unaugmented tests. Regressions take the following form:

$$
\begin{gathered}
\Delta p_{t}=\alpha_{p}+\sum_{s=1}^{n 1} \beta_{1 s} \Delta p_{t-s}+\beta_{2} e c_{p, t-1}+\sum_{s=1}^{n 3} \beta_{3 s} \Delta u l c_{t-s}+\varepsilon_{p t} \\
\Delta u c_{t}=\mu_{w}+\sum_{s=1}^{n 1} \lambda_{1 s} \Delta u l c_{t-s}+\lambda_{2} e c_{w, t-1}+\sum_{s=1}^{n 3} \lambda_{3 s} \Delta p_{t-s}+\varepsilon_{w t} .
\end{gathered}
$$

The dependent variable is the first difference of the log CPI. The error-correction term $\left(e c_{p, t-1}\right)$ measures the impact on the dependent variable of any deviations from the cointegration path, while lagged changes in wages capture the short-term dynamics. Similarly, ULC changes are only regressed on lagged ULC changes, the error-correction term and the CPI in first differences. $n 1$ is determined on the basis of the Schwarz information criterion, while $n 3$ is set equal to four. Panel I of Table 5 below reports the results for the coefficients of interest only: $\beta_{2}, \beta_{3 s}, \lambda_{3}$ and $\lambda_{3 s}$. The ${ }^{*}$ symbol implies significance at the $10 \%$ level while the ${ }^{* *}$ symbol implies significance at the $5 \%$ level. From these benchmark regressions, it appears that unit labour costs influence prices via both the error-correction term and the first lag of their changes. In turn, unit labour costs also adjust to the first lag of price changes as well as to the error correction-term.

In the subsequent step, we want to check whether these results are robust to sample modifications. As can be observed in the charts of section 3.2, after the disinflation phases of the beginning of the 1990, the Swiss economy has experienced a period of low and stable inflation. Year-on-year CPI changes averaged 3.3\% between 1975:1 and 1990:4. In the second part of our sample (1991:12005:4) average headline inflation declined to $1.6 \%$. If we only include the period after 1994:1, i.e. the moment when inflation slipped back below the $2 \%$ threshold, the average CPI increase is $0.9 \%$. The volatility of inflation is also significantly lower than in the previous period. One might therefore wonder 
Table 5: Unaugmented Granger Causality Tests

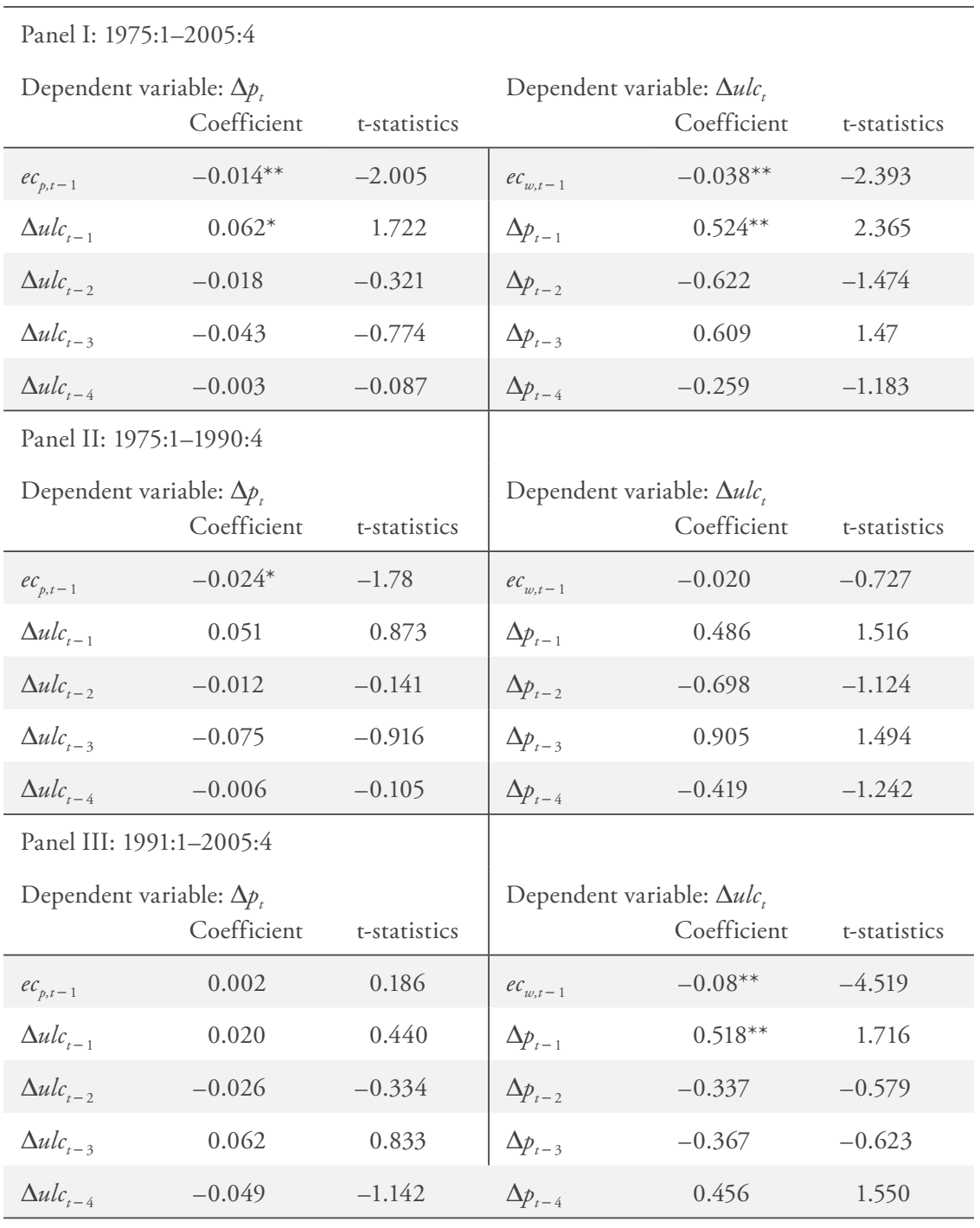

** $\left(^{*}\right)$ signals significance at the $5 \%(10 \%)$ level. 
whether the wage-price link has undergone any modifications in this lower inflation environment.

Sub-sample results are presented in panels II and III of Table 5. Unit labour costs maintain their explanatory power in the first part of the sample via the error correction term, whereas unit labour cost changes are not significant. By contrast, in the 1991:1-2005:4 sub-sample unit labour costs do not appear to be significant at all. As far as prices are concerned, the opposite outcome is observed. Prices Granger cause unit labour costs only in the second part of the sample. All in all, the result of a bi-directional influence between wages and prices does not seem to be robust to sample modifications in this first set of regressions.

In order to obtain further insights, we implement Granger causality tests within the Phillips curve framework introduced in section 2.1. Accordingly, we run the following regressions:

$$
\begin{aligned}
\Delta p_{t}= & \alpha_{p}+\sum_{s=1}^{n 1} \beta_{1 s} \Delta p_{t-s}+\beta_{2} e c_{p, t-1}+\sum_{s=1}^{n 3} \beta_{3 s} \Delta u l c_{t-s} \\
& +\sum_{s=1}^{n 4} \beta_{4 s} O G a p_{t-s}+\sum_{s=1}^{n 5} \beta_{5 s} \Delta M 1_{t-s}+\sum_{s=0}^{n 6} \beta_{6 s} \Delta R P_{t-s}+\varepsilon_{p t} \\
\Delta u l c_{t}= & \mu_{w}+\sum_{s=1}^{n 1} \lambda_{1 s} \Delta u l c_{t-s}+\lambda_{2} e c_{w, t-1}+\sum_{s=1}^{n 3} \lambda_{3 s} \Delta p_{t-s} \\
& +\sum_{s=1}^{n 4} \lambda_{4 s} O G a p_{t-s}+\sum_{s=1}^{n 5} \lambda_{5 s} \Delta M 1_{t-s}+\sum_{s=0}^{n 6} \lambda_{6 s} \Delta R P_{t-s}+\varepsilon_{w t}
\end{aligned}
$$

As compared with the specification of (9) and (10), additional variables are taken into account. $O G a p_{t}$ is a measure of the output gap and reflects the state of cyclical demand from the real economy side, whereas $\Delta M 1_{t}$ is money supply growth and is meant to capture the impact of monetary conditions. $\Delta R P_{t}$ is a relative price change, where relative prices are defined as the ratio of the imported CPI components over total CPI. This variable is used to capture supply shock effects and exchange rate effects, which are particularly relevant in a small open economy. Again, the number of lags for the exogenous variables was set to four in the reported equations. Other lag structures were tested with no significant impact on the results. 
Table 6 shows the estimated coefficients along with the corresponding $t$-values for the full sample. The estimated constants as well as the coefficients of the lagged dependent variables are not reported. The bottom of the table provides the $p$-values of the Wald tests in which we set, for each of the relevant explanatory variable, all the coefficients equal to zero simultaneously.

In the price equation, price changes appear to be influenced by ULC via the error-correction term only. The individual coefficients of lagged short-run changes in ULC are not significant. Also, the outcome of the Wald test does not allow the restriction that all ULC coefficients are jointly equal to zero to be rejected. In fact, the null hypothesis that coefficients are jointly equal to zero can only be rejected for the relative prices variable. Thus, all in all, there is a clear causality effect that runs from ULC to price changes via the error correction term but there is no evidence regarding the influence of ULC growth.

We now turn to the wage equation. According to the $p$-values of the single coefficients, the error correction term is strongly significant and so are price changes in the previous quarter. The results of the Wald tests confirm the impact of lagged price changes on ULC growth. Therefore, in the short run, ULC seem to adjust to movements in prices via both the long-run cointegration relation and $\mathrm{CPI}$ quarterly changes. The output gap and relative price changes also appear to influence unit labour cost growth.

Tables 7 and 8 present regression results for the previously defined sub-samples. In the price equation for the lower part of the sample, ULC have a significant influence on price changes via the error-correction term but not via the short-run ULC dynamics. By contrast, in the upper part of the sample, the explanatory contribution of both wage related variables becomes clearly non-significant.

In the wage equation of tables 7 and 8, the error correction term remains significant in both sub-periods. According to the Wald test, the estimated coefficients for price changes are also significant, in both the 1975:1-1990:4 and 1991:1-2005:4 sub-samples.

All in all, there is evidence that price changes maintain an impact on ULC short-run changes during both higher and lower inflation periods. By contrast, in a context of persistently low inflation, productivity-adjusted wage changes seem to lose their meaning as an indicator for short-run price developments. As described in section 2.2, recent work on US data also tend to show that wage measures have a significant impact on price changes only in periods of relatively high inflation.

One could object that estimation errors in the data construction for ULC might affect the Granger-causality results, as our Granger-causality tests take 
Table 6: Regressions' Results, 1975:1-2005:4

\begin{tabular}{|c|c|c|c|}
\hline \multicolumn{2}{|l|}{$\begin{array}{r}\text { Dependent variable: } \Delta p_{t} \\
\text { Coefficient }\end{array}$} & $\begin{array}{r}\text { Dependent variable: } \Delta u c_{t} \\
\text { Coefficient }\end{array}$ & t-statistics \\
\hline$-0.015^{* *}$ & -2.604 & $-0.070^{* *}$ & -3.992 \\
\hline$\Delta u l c_{t-1}$ & 1.582 & $0.899^{* *}$ & 2.735 \\
\hline$\Delta u l c_{t-2}$ & -1.302 & -0.866 & -1.299 \\
\hline$\Delta u l c_{t-3}$ & 0.525 & $\Delta p_{t-3}$ & 0.727 \\
\hline$\Delta u l c_{t-4}$ & 0.273 & -0.214 & -0.666 \\
\hline$O G a p_{t-1}$ & 0.594 & $O G a p_{t-1}$ & 0.887 \\
\hline$O G a p_{t-2}$ & -0.789 & $O G a p_{t-2}$ & -0.917 \\
\hline$O G a p_{t-3}$ & 1.228 & $O G a p_{t-3}$ & 1.792 \\
\hline$O G a p_{t-4}$ & -1.348 & $-0.004^{* *}$ & -2.245 \\
\hline$\Delta M 1_{t-1}$ & 0.327 & $\Delta M 1_{t-1}$ & 0.469 \\
\hline$\Delta M 1_{t-2}$ & -0.911 & $\Delta M 1_{t-2}$ & 0.511 \\
\hline$\Delta M 1_{t-3}$ & 0.934 & $\Delta M 1_{t-3}$ & -1.129 \\
\hline$\Delta M 1_{t-4}$ & -0.645 & $\Delta M 1_{t-4}$ & 1.820 \\
\hline $0.358^{* *}$ & 13.278 & $0.146^{*}$ & 1.730 \\
\hline$-0.554^{* *}$ & -8.457 & $-0.596^{* *}$ & -2.913 \\
\hline $0.450^{* *}$ & 4.845 & $\Delta R P_{t-2}$ & 1.554 \\
\hline$-0.203^{* *}$ & -2.492 & $\Delta R P_{t-3}$ & -0.725 \\
\hline$\Delta R P_{t-4}$ & 2.094 & $\Delta R P_{t-4}$ & 0.213 \\
\hline $\begin{array}{l}H_{0}: \beta_{31}=\beta_{32}=\beta_{33}=\beta_{34}=0 \\
\text { p-value } \quad 0.5609\end{array}$ & & $\begin{array}{l}H_{0}: \lambda_{31}=\lambda_{32}=\lambda_{33}=\lambda_{34}=0 \\
\text { p-value } \\
0.0014\end{array}$ & \\
\hline $\begin{array}{l}H_{0}: \beta_{41}=\beta_{42}=\beta_{43}=\beta_{44}=0 \\
\text { p-value } \\
0.1518\end{array}$ & & $\begin{array}{l}H_{0}: \lambda_{41}=\lambda_{42}=\lambda_{43}=\lambda_{44}=0 \\
\text { p-value } \\
0.0000\end{array}$ & \\
\hline $\begin{array}{lc}H_{0}: \beta_{51}=\beta_{52}=\beta_{53}= & \beta_{54}=0 \\
\text { p-value } & 0.8087\end{array}$ & & $\begin{array}{lr}H_{0}: \lambda_{51}=\lambda_{52}=\lambda_{53}= & \lambda_{54}=0 \\
\text { p-value } & 0.3519\end{array}$ & \\
\hline $\begin{array}{l}H_{0}: \beta_{60}=\beta_{61}=\beta_{62}=\beta_{63}=\beta_{6} \\
\text { p-value } \quad 0.0000\end{array}$ & & $\begin{array}{l}H_{0}: \lambda_{60}=\lambda_{61}=\lambda_{62}=\lambda_{63}=\lambda_{64} \\
\text { p-value } \\
0.0127\end{array}$ & \\
\hline
\end{tabular}

** $\left(^{*}\right)$ signals significance at the 5\% (10\%) level. 
Table 7: Regressions' Results, 1975:1-1990:4

\begin{tabular}{|c|c|c|c|c|c|}
\hline \multicolumn{3}{|c|}{ Dependent variable: $\Delta p_{t}$} & \multicolumn{3}{|c|}{ Dependent variable: $\Delta u l_{t}$} \\
\hline$e c_{p, t-1}$ & $-0.022^{*}$ & -1.879 & $e c_{w, t-1}$ & $-0.116^{* *}$ & -3.275 \\
\hline$\Delta u l c_{t-1}$ & 0.074 & 0.459 & $\Delta p_{t-1}$ & $1.010^{*}$ & 1.745 \\
\hline$\Delta u l c_{t-2}$ & -0.111 & -0.657 & $\Delta p_{t-2}$ & -0.685 & -0.623 \\
\hline$\Delta u l c_{t-3}$ & 0.034 & 0.293 & $\Delta p_{t-3}$ & 0.601 & 0.569 \\
\hline$\Delta u l c_{t-4}$ & -0.002 & -0.052 & $\Delta p_{t-4}$ & -0.299 & -0.550 \\
\hline$O G a p_{t-1}$ & -0.0004 & -0.026 & $O G a p_{t-1}$ & 0.000 & 0.045 \\
\hline$O G a p_{t-2}$ & -0.0007 & -0.241 & $O G a p_{t-2}$ & -0.007 & -0.676 \\
\hline$O G a p_{t-3}$ & 0.001 & 0.518 & $O G a p_{t-3}$ & 0.014 & 1.549 \\
\hline$O G a p_{t-4}$ & -0.001 & -0.451 & $O G a p_{t-4}$ & -0.005 & -1.175 \\
\hline$\Delta M 1_{t-1}$ & 0.008 & 0.460 & $\Delta M 1_{t-1}$ & 0.024 & 0.398 \\
\hline$\Delta M 1_{t-2}$ & $-0.056^{*}$ & -1.821 & $\Delta M 1_{t-2}$ & 0.116 & 1.116 \\
\hline$\Delta M 1_{t-3}$ & 0.043 & 1.459 & $\Delta M 1_{t-3}$ & -0.141 & -1.405 \\
\hline$\Delta M 1_{t-4}$ & $-0.031^{*}$ & -1.780 & $\Delta M 1_{t-4}$ & $0.144^{* *}$ & 2.547 \\
\hline$\Delta R P_{t}$ & $0.378^{* *}$ & 9.788 & $\Delta R P_{t}$ & $0.322^{* *}$ & 2.456 \\
\hline$\Delta R P_{t-1}$ & $-0.509^{* *}$ & -4.782 & $\Delta R P_{t-1}$ & $-0.900^{* *}$ & -2.504 \\
\hline$\Delta R P_{t-2}$ & $0.411^{* *}$ & 2.490 & $\Delta R P_{t-2}$ & 0.682 & 1.232 \\
\hline$\Delta R P_{t-3}$ & -0.209 & -1.335 & $\Delta R P_{t-3}$ & -0.399 & -0.765 \\
\hline$\Delta R P_{t-4}$ & 0.075 & 0.853 & $\Delta R P_{t-4}$ & 0.233 & 0.854 \\
\hline $\begin{array}{l}H_{0}: \beta_{31}=\beta \\
\text { p-value }\end{array}$ & $\begin{array}{c}=\beta_{34}=0 \\
0.9602\end{array}$ & & $\begin{array}{l}H_{0}: \lambda_{31}=\lambda \\
\text { p-value }\end{array}$ & $\begin{array}{r}=\lambda_{34}=0 \\
0.0415\end{array}$ & \\
\hline $\begin{array}{l}H_{0}: \beta_{41}=\beta \\
\text { p-value }\end{array}$ & $\begin{array}{c}{ }_{43}=\beta_{44}=0 \\
0.9611\end{array}$ & & $\begin{array}{l}H_{0}: \lambda_{41}=\lambda \\
\text { p-value }\end{array}$ & $\begin{array}{r}{ }_{3}=\lambda_{44}=0 \\
0.0005\end{array}$ & \\
\hline $\begin{array}{l}H_{0}: \beta_{51}=\beta \\
\text { p-value }\end{array}$ & $\begin{array}{c}=\beta_{54}=0 \\
0.0323\end{array}$ & & $\begin{array}{l}H_{0}: \lambda_{51}=\lambda \\
\text { p-value }\end{array}$ & $\begin{array}{r}=\lambda_{54}=0 \\
\\
0.0268\end{array}$ & \\
\hline $\begin{array}{l}H_{0}: \beta_{60}=\beta \\
\text { p-value }\end{array}$ & $\begin{array}{c}{ }_{62}=\beta_{63}=\beta_{64} \\
0.0000\end{array}$ & & $\begin{array}{l}H_{0}: \lambda_{60}=\lambda \\
\text { p-value }\end{array}$ & $\begin{aligned} 2 & =\lambda_{63}=\lambda_{64} \\
& 0.0483\end{aligned}$ & \\
\hline
\end{tabular}

** $\left.{ }^{*}\right)$ signals significance at the 5\% (10\%) level. 
Table 8: Regressions' Results, 1991:1-2005:4

\begin{tabular}{|c|c|c|c|c|c|}
\hline \multicolumn{2}{|c|}{$\begin{array}{r}\text { Dependent variable: } \Delta p_{t} \\
\text { Coefficient }\end{array}$} & t-statistics & \multicolumn{2}{|c|}{$\begin{array}{r}\text { Dependent variable: } \Delta u l_{t} \\
\text { Coefficient }\end{array}$} & \multirow{2}{*}{$\frac{{ }^{t} \text {-statistics }}{-1.9805}$} \\
\hline$e c_{p, t-1}$ & -0.017 & -1.3914 & $e c_{w, t-1}$ & $-0.061^{*}$ & \\
\hline$\Delta u l c_{t-1}$ & -0.137 & -1.4885 & $\Delta p_{t-1}$ & 0.610 & 1.578128 \\
\hline$\Delta u l c_{t-2}$ & 0.209 & 1.5475 & $\Delta p_{t-2}$ & -0.280 & -0.359069 \\
\hline$\Delta u l c_{t-3}$ & -0.116 & -0.8494 & $\Delta p_{t-3}$ & -0.092 & -0.120648 \\
\hline$\Delta u l c_{t-4}$ & 0.037 & 0.5928 & $\Delta p_{t-4}$ & -0.013 & -0.036498 \\
\hline$O G a p_{t-1}$ & -0.001 & -0.9652 & $O G a p_{t-1}$ & -0.005 & -2.169106 \\
\hline$O G a p_{t-2}$ & 0.002 & 0.8188 & $O G a p_{t-2}$ & 0.011 & 2.162702 \\
\hline$O G a p_{t-3}$ & 0.0003 & 0.1704 & $O G a p_{t-3}$ & -0.007 & -1.397481 \\
\hline$O G a p_{t-4}$ & -0.001 & -0.9060 & $O G a p_{t-4}$ & 0.003 & 1.080514 \\
\hline$\Delta M 1_{t-1}$ & -0.021 & -1.6009 & $\Delta M 1_{t-1}$ & $-0.079^{* *}$ & -2.27485 \\
\hline$\Delta M 1_{t-2}$ & $0.042^{*}$ & 1.9655 & $\Delta M 1_{t-2}$ & 0.090 & 1.681299 \\
\hline$\Delta M 1_{t-3}$ & -0.023 & -1.1111 & $\Delta M 1_{t-3}$ & -0.074 & -1.385628 \\
\hline$\Delta M 1_{t-4}$ & 0.005 & 0.4552 & $\Delta M 1_{t-4}$ & -0.005 & -0.146855 \\
\hline$\Delta R P_{t}$ & $0.386^{* *}$ & 6.0942 & $\Delta R P_{t}$ & -0.150 & -0.828985 \\
\hline$\Delta R P_{t-1}$ & $-0.617^{* *}$ & -4.5424 & $\Delta R P_{t-1}$ & -0.106 & -0.347997 \\
\hline$\Delta R P_{t-2}$ & $0.561^{* *}$ & 3.4818 & $\Delta R P_{t-2}$ & 0.345 & 0.93971 \\
\hline$\Delta R P_{t-3}$ & $-0.379^{* *}$ & -2.9853 & $\Delta R P_{t-3}$ & -0.539 & -1.623603 \\
\hline$\Delta R P_{t-4}$ & $0.195^{* *}$ & 2.6488 & $\Delta R P_{t-4}$ & $0.382^{*}$ & 1.791012 \\
\hline \multicolumn{3}{|c|}{$\begin{array}{l}H_{0}: \beta_{31}=\beta_{32}=\beta_{33}=\beta_{34}=0 \\
\text { p-value } \\
0.4390\end{array}$} & \multicolumn{3}{|c|}{$\begin{array}{l}H_{0}: \lambda_{31}=\lambda_{32}=\lambda_{33}=\lambda_{34}=0 \\
\text { p-value }\end{array}$} \\
\hline \multicolumn{3}{|c|}{$\begin{array}{l}H_{0}: \beta_{41}=\beta_{42}=\beta_{43}=\beta_{44}=0 \\
\mathrm{p} \text {-value } \quad 0.0123\end{array}$} & \multicolumn{3}{|c|}{$\begin{array}{lc}H_{0}: \lambda_{41}=\lambda_{42}=\lambda_{43}= & \lambda_{44}=0 \\
\text { p-value } & 0.0036\end{array}$} \\
\hline \multicolumn{3}{|c|}{$\begin{array}{l}H_{0}: \beta_{51}=\beta_{52}=\beta_{53}=\beta_{54}=0 \\
\text { p-value } \\
0.1864\end{array}$} & \multicolumn{3}{|c|}{$\begin{array}{lr}H_{0}: \lambda_{51}=\lambda_{52}=\lambda_{53}= & \lambda_{54}=0 \\
\text { p-value } & 0.1095\end{array}$} \\
\hline \multicolumn{3}{|c|}{$\begin{array}{l}H_{0}: \beta_{60}=\beta_{61}=\beta_{62}=\beta_{63}=\beta_{64}=0 \\
\mathrm{p} \text {-value } \quad 0.0000\end{array}$} & \multicolumn{3}{|c|}{$\begin{array}{l}H_{0}: \lambda_{60}=\lambda_{61}=\lambda_{62}=\lambda_{63}=\lambda_{64}=0 \\
\text { p-value }\end{array}$} \\
\hline
\end{tabular}

** $\left.{ }^{*}\right)$ signals significance at the $5 \%(10 \%)$ level. 
the ULC data as given and do not account for the first-step estimation. ${ }^{8}$ Several steps were taken to dispel - as far as possible - this doubt. The first element is the accuracy of the disaggregation procedure. Section 3.1 presents our arguments in detail. Second, in order to further reduce this risk, we introduced four lags of ULC changes in our price equations. Third, a robustness check was implemented. More specifically, we reestimated equations (11) and (12) using a ULC measure based on quarterly SUVA wages. If the Chow-Lin procedure is successful in adding useful information to this basic ULC measure, regressions based on SUVA-derived ULC should produce similar but weaker results than those we have presented so far. Although we do not reproduce the results of these regressions here, they are fully in line with this assumption.

\section{Concluding Remarks}

We explored the link between wages and prices with the purpose of identifying the causality effects at work. We were particularly interested in gauging the information content of wage dynamics for short-run CPI inflation developments. We can summarise our findings as follows.

Our Phillips-curve estimates show that prices have a systematic impact on wages. Throughout the whole period, 1975-2005, prices always help to explain productivity-adjusted wage changes via both the error-correction term, measuring deviations from the long-run cointegration equilibrium, and short-run price changes. This outcome is robust across sub-samples.

Our findings also support the view that productivity-adjusted wage growth has a Granger-causality effect on CPI inflation. In particular, estimations over the entire period show that deviations from the cointegration path provide useful information about future price movements. This would, in principle, suggest that ULC developments are indeed a helpful complement to the set of indicators that inflation watchers should monitor. This outcome, however, does not seem to hold across sub-samples. Results for the period beginning with the disinflation phases in the early 1990s indicate that both wage growth and the error-correction term lack explanatory power when inflation is low and little volatile. In such an environment, other factors - such as relative price changes or the output gap - clearly dominate wages as explanatory variables for short-run CPI movements. 


\section{References}

Aaronson, Daniel (2001), "Price Pass-Through and the Minimum Wage", Review of Economics and Statistics, 83 (1), pp. 158-169.

Barcellan, Roberto (1994), ECOTRIM: A Program for Temporal Disaggregation of Time Series, Eurostat, Luxembourg.

Bardsen, Gunnar, Oyvind Eitrheim, Eilev Jansen and Ragnar Nymoen (2005), The Econometrics of Macroeconomic Modelling, New York.

Barth, James R. and James T. Bennet (1975), "Cost-push versus Demand-pull Inflation: Some Empirical Evidence”, Journal of Money, Credit and Banking, 7 (3), pp. 391-397.

Blanchard, Olivier J. and Lawrence F. Katz (1999), "Wage Dynamics: Reconciling Theory and Evidence", NBER working paper N o. 6924.

Brauer, Davide A. (1997), "Do Rising Labor Costs Trigger Higher Inflation?”, Current Issues, Federal Reserve Bank of New York.

Brayton, Flint, John M. Roberts and John C. Williams (1999), "What's Happened to the Phillips Curve?", Finance and Economics Discussion Series, Federal Reserve Board, Washington.

Chan-Lau, Jorge A. and Stephen Tokarick (1999), "Why Has Inflation in the United States Remained So Low? Reassessing the Importance of Labor Costs and Price of Imports", IMF Working Paper.

Chow, Gregory.C. and An-Loh Lin (1971), "Best Linear Unbiased Interpolation, Distribution and Extrapolation of Time Series by Related Series", The Review of Economics and Statistics, 53 (4), pp.372-375.

Emery, Kenneth M. and Chin-Ping Chang (1996), "Do Wages Help Predict Inflation?", Economic Review, Federal Reserve Bank of Dallas, pp. 2-9.

Eurostat (1999), Handbook on Quarterly National Accounts, Luxembourg.

Gaillard, Serge (1992), „Lohn- und Preisdynamik: Eine empirische Studie für die Schweiz", KOF/ETH Working Paper, No. 43.

Ghali, Khalifa (1999), "Wage Growth and the Inflation Process: A Multivariate Cointegration Analysis", Journal of Money, Credit and Banking, 31 (3), pp. 417-431.

Gordon, Robert J. (1988), “The Role of Wages in the Inflation Process”, American Economic Review, 78 (2), pp. 276-283.

Gordon, Robert J. (1985), “Understanding Inflation in the 1980s", Brookings Papers on Economic Activity, 1, pp. 263-269.

Hess, Gregory D. and Mark E. Schweitzer (2000), "Does Wage Inflation Cause Price Inflation?", Policy Discussion Paper, Federal Reserve Bank of Cleveland, No. 1. 
Layard, Richard and Stephen Nickell (1986), "Unemployment in Britain", Economica, 53, pp. 121-169.

Layard, Richard, Stephen Nickell and Richard Jackman (1991), Unemployment: Macroeconomic Performance and the Labour Market, New York.

Menra, Yash (2000), "Wage-Price Dynamics: Are They Consistent with Cost Push?”, Economic Quarterly, Federal Reserve Bank of Richmond, 86, pp. 27-43.

Menra, Yash (1993), “Unit Labor Costs and the Price Level”, Economic Quarterly, Federal Reserve Bank of Richmond, 79, pp. 35-51.

Menra, Yash (1991), "Wage Growth and the Inflation Process: An Empirical Note", American Economic Review, 81 (4), pp. 931-937.

Oxley, Les and Michael McAleer, 1993, "Econometric Issues in Macroeconomic Models with Generated Regressors", Journal of Economic Surveys, 7 (1), p p. 1-40.

\section{SUMMARY}

We construct a quarterly time series for nominal hourly wages and unit labour costs from 1975 onwards and investigate the empirical link between wages and CPI inflation in Switzerland in order to identify causality effects and assess the relevance of wages as an indicator for short-run price changes. We find evidence that prices systematically influence wages whereas the influence of wages on prices is much more sensitive to the choice of the sample period. In particular, the explanatory power of wages disappears in a low inflation environment. These findings move in the same direction as most evidence obtained with US data. 